\title{
Structure, Morphology, and Mechanical Properties of AICrN Coatings Deposited by Cathodic Arc Evaporation
}

Adam Gilewicz, Roman Jedrzejewski, Piotr Myslinski, and Bogdan Warcholinski

\author{
(Submitted July 30, 2018; in revised form December 12, 2018; published online February 14, 2019)
}

\begin{abstract}
AICrN coatings were deposited on steel substrates (HS6-5-2) using cathodic arc evaporation. The effect of nitrogen pressure on the properties of CrAIN coatings formed from $\mathrm{Al}_{\mathbf{8 0}} \mathrm{Cr}_{20}$ cathode, such as chemical and phase composition of the coatings, surface morphology, deposition rate, hardness and adhesion to the substrate, and friction and wear were investigated. The coating deposited at nitrogen pressure of 3 Pa shows the highest deposition rate. The roughness parameter $R a$ of the coating surface decreases with increasing nitrogen pressure during its formation. The test results showed that the AICrN coatings deposited under nitrogen pressure in the range from 1 to 5 Pa show similar hardness for all the coatings, which is around $17 \mathrm{GPa}$. The increase in the negative bias voltage of the substrate during the formation of the coating deteriorates its adhesion to the substrate, although the wear rate is rather good, about $1.4 \times 10^{-7} \mathrm{~mm}^{3} / \mathrm{Nm}$. The coatings deposited at nitrogen pressure of 3-4 Pa are characterized by the highest critical load, $95 \mathrm{~N}$. Despite worse adhesion, these coatings are characterized by high resistance to wear, the wear rate is about $1.4 \times 10^{-7} \mathrm{~mm}^{3} / \mathrm{Nm}$.
\end{abstract}

Keywords adhesion, $\mathrm{AlCrN}$, hardness, morphology, structure

\section{Introduction}

Chromium nitride coatings are used extensively in metalworking due to its good mechanical and tribological properties as well as corrosion resistance (Ref 1-5). The industry requirements related to the increase in efficiency and speed of machining processes make the problem of durability and reliability of cutting tools extremely important. Not all coating materials meet these requirements. $\mathrm{CrN}$ is applied to protect cutting tools, but their hardness and oxidation resistance are not always enough to meet the requirement of modern mechanical machining. There are different ways to improve mechanical and tribological properties of the coatings. One of the methods is addition of metallic or non-metal elements such as $\mathrm{Ti}, \mathrm{Si}, \mathrm{Ta}$, $\mathrm{Al}, \mathrm{Nb}, \mathrm{C}, \mathrm{B}$ to $\mathrm{CrN}$. It is known that better coating properties are strongly associated with its unique microstructure.

One of the most promising ternary systems is Al-Cr-N. $\mathrm{AlCrN}$ is particularly attractive due to their excellent resistance to oxidation and mechanical properties as well as chemical stability (Ref 6). AlCrN has better wear resistance due to the formation of permanent oxide layers on the worn surfaces. Adding aluminum to $\mathrm{CrN}$ increases wear resistance at high temperatures ( $\operatorname{Ref} 7)$. AlCrN coatings show very high hardness at elevated temperatures and resistance to wear under extreme mechanical stress. The properties depend on the aluminum

Adam Gilewicz, Piotr Myslinski, and Bogdan Warcholinski, Faculty of Technology and Education, Koszalin University of Technology, Koszalin, Poland; and Roman Jedrzejewski, Faculty of Mechanical Engineering and Mechatronics, West Pomeranian University of Technology Szczecin, Szczecin, Poland. Contact e-mail: bogdan.warcholinski@tu.koszalin.pl. concentration in the coatings. Below $75 \%$ of $\mathrm{Al}$ in $\mathrm{CrN}$ a regular c-AlN phase is formed ( $\operatorname{Ref} 8,9)$. Al-Cr-N coatings, compared to $\mathrm{CrN}$, TiN and TiAlN, are characterized by resistance to oxidation up to $850-900{ }^{\circ} \mathrm{C}(\operatorname{Ref} 10,11)$ and almost constant hardness up to $800{ }^{\circ} \mathrm{C}$ (Ref 12). Increase in aluminum concentration promotes the formation of the hexagonal phase of h-AlN and reducing the hardness of coatings and leading to drastic degradation in the strength (Ref 13). The hexagonal AIN phase is more stable than the cubic phase, thus the transformation of the cubic to hexagonal phase will occur spontaneously. Thus, at elevated temperatures c-AlN $\rightarrow$ hAlN phase transformation occurs (Ref 13). Cubic structure shows improvement in wear resistance and thermal stability compared to the hexagonal structure (Ref 14).

AlCrN coatings can be produced by various methods, including magnetron sputtering (Ref 14-18), HIPIMS (Ref 19$21)$ and cathodic arc evaporation (Ref 8, 9, 22-25). Dependent on the deposition method applied and the technological parameters of coating deposition, different structure and mechanical properties can be obtained.

The coatings deposited using magnetron sputtering from $\mathrm{Al}_{70} \mathrm{Cr}_{30}$ cathode are characterized by the hardness of about $22 \mathrm{GPa}$ (Ref 14). Wang et al. (Ref 16) found that hardness strongly depends on the negative substrate bias voltage. For low $U_{\mathrm{B}}$ ranged from 40 to $160 \mathrm{~V}$, hardness of $\mathrm{AlCrN}$ coatings is relatively small, about $10-13 \mathrm{GPa}$ and increases to about $25 \mathrm{GPa}$ for $U_{\mathrm{B}}=-260 \mathrm{~V}$.

Reiter et al. (Ref 8) indicated that the hardness of Al-Cr-N coatings, deposited using cathodic arc evaporation, with $\mathrm{Al}$ concentration of about 46 and 71 at.\% increases of about $80 \%$ compared to $\mathrm{CrN}$ coating. Hardness and elastic modulus of the coating deposited on the surface of plasma nitrocarburized cool-work tool steels from $\mathrm{Al}_{70} \mathrm{Cr}_{30}$ cathode are about 42 and $289 \mathrm{GPa}$, respectively (Ref 24). Lower hardness, about $27 \mathrm{GPa}$, was measured for coating deposited on nitrided high carbon steel (Ref 25). The same cathode was applied to deposit the coating on a carbide tool insert and the hardness was $31 \mathrm{GPa}$ (Ref 23). 
Bobzin et al. (Ref 19) found that hardness of $\mathrm{AlCrN}$ coatings deposited with $\mathrm{Al}_{70} \mathrm{Cr}_{30}$ and $\mathrm{Al}_{80} \mathrm{Cr}_{20}$ target compositions by high power pulsed magnetron sputtering strongly depends on pulse length. For the pulse length of $200 \mu \mathrm{s}$, the hardness of the coatings for both targets was about $15 \mathrm{GPa}$. For reduced pulse length to $40 \mu \mathrm{s}$ the hardness increases to about $25 \mathrm{GPa}\left(\mathrm{Al}_{80} \mathrm{Cr}_{20}\right)$ and about $30 \mathrm{GPa}\left(\mathrm{Al}_{70} \mathrm{Cr}_{30}\right)$. It is connected with increased peak power density with decreased pulse length. The investigations of Bagcivan et al. (Ref 21) confirm above findings for the coatings deposited using $\mathrm{Al}_{20} \mathrm{Cr}_{80}$ cathode.

The tribological properties of AlCrN coatings were investigated using different methods, parameters of the tests, and different counterbodies. They depend both on parameters of the test (Ref 26) and chemical and phase composition of the coatings (Ref 8, 27). The results are ranged from $16 \times 10^{-6}(\operatorname{Ref} 13)$ to $2 \times 10^{-7} \mathrm{~mm}^{3} / \mathrm{Nm}$ (Ref 28). Investigations of Antonov et al. (Ref 26) on $\mathrm{Al}_{60} \mathrm{Cr}_{40} \mathrm{~N}$ coatings deposited by cathodic arc evaporation using three counterparts $\left(\mathrm{ZrO}_{2}, \mathrm{Si}_{3} \mathrm{~N}_{4}, \mathrm{Al}_{2} \mathrm{O}_{3}\right)$ indicate that the highest wear rate, ranged from $9 \times 10^{-5}$ to $5 \times 10^{-6} \mathrm{~mm}^{3} / \mathrm{Nm}$, was for $\mathrm{ZrO}_{2}$ counterpart. Similar values were observed for $\mathrm{Si}_{3} \mathrm{~N}_{4}$ counterpart. In case of $\mathrm{Al}_{2} \mathrm{O}_{3}$, the wear rate was about one level lower, from $3 \times 10^{-6}$ to $2 \times 10^{-7} \mathrm{~mm}^{3} / \mathrm{Nm}$. The wide range of wear rate values is connected with applied sliding speed, from 0.002 to $1.458 \mathrm{~m} / \mathrm{s}$.

The scratch test and Daimler-Benz indentation test are generally applied as a simple and effective methods in evaluating adhesion strength. The adhesion of AlCrN coatings was not systematically investigated. Polcar et al. (Ref 29) found critical load $\mathrm{Lc}_{2}$, related to coating delamination and considered as adhesion strength of coatings, for $\mathrm{Al}_{55} \mathrm{Cr}_{45} \mathrm{~N}$ coating deposited on WC substrates by cathodic arc is about $70 \mathrm{~N}$. Wang et al. (Ref 13) stated that $\mathrm{Lc}_{2}$ for coatings deposited by multi-arc ion plating on WC substrates from $\mathrm{Al}_{67} \mathrm{Cr}_{33}$ cathode ranges from 44 to $59 \mathrm{~N}$ dependent on substrate bias voltage and nitrogen partial pressure.

The mechanical and tribological properties strongly depend on chemical composition of the coatings.

Despite extensive testing of AlCrN coatings, there are only a few articles dedicated to their deposition in a wide range of nitrogen pressure (Ref $13,18,30)$. We state, that most of them concern the formation of $\mathrm{AlCrN}$ coatings by magnetron sputtering. Therefore, we decided to form AlCrN coatings by means of arc deposition technique in a wide range of nitrogen pressure to obtain samples for comprehensive testing including adhesion, and especially wear. To the best of our knowledge, the wear resistance of AlCrN coatings deposited by arc using the $\mathrm{Al}_{80} \mathrm{Cr}_{20}$ target has not yet been studied systematically.

The aim of the work is to determine the effect of AlCrN deposition parameters on its structure, morphology and mechanical properties. The coatings were obtained by the cathodic arc sputtering method using $\mathrm{Al}_{80} \mathrm{Cr}_{20}$ target on HS6-52 high-speed steel substrates. The variable parameter during the coating process - nitrogen pressure ranges from 1 to $5 \mathrm{~Pa}$.

\section{Experimental}

\subsection{Coating Deposition}

AlCrN coatings were deposited by cathodic arc evaporation on HS6-5-2 steel substrates using a semi-industrial TINA
$900 \mathrm{M}$ device (Ref 31). AlCr alloy cathodes (80:20) with a purity of $99.99 \%$ with a diameter of $100 \mathrm{~mm}$ were applied. Substrates with a diameter of $32 \mathrm{~mm}$ and a thickness of $3 \mathrm{~mm}$ were ground and polished to a roughness parameter $\mathrm{Ra}$ of approx. $0.02 \mu \mathrm{m}$, and then they were washed in an alkaline bath in an ultrasonic bath, rinsed in deionized water and dried by warm air. The substrates were mounted on a rotating holder parallel to the surface of the evaporated cathode, in the working chamber at a distance of $18 \mathrm{~cm}$ from the sources.

The vacuum chamber was evacuated to a base pressure of $1 \mathrm{mPa}$. Then the substrates were heated to a temperature of about $350{ }^{\circ} \mathrm{C}$. The process of coating deposition was preceded by etching by argon and chromium ions under conditions: voltage $-600 \mathrm{~V}$, argon pressure in the chamber $0.5 \mathrm{~Pa}$, time $10 \mathrm{~min}$. The $\mathrm{Cr}$ arc current was $80 \mathrm{~A}$. The purpose of etching was to remove weakly bound particles from the etched surface. A thin layer of chromium to improve the adhesion of the coatings to the substrate, approximately $0.1 \mu \mathrm{m}$ thick, was deposited to the substrate before proper coating. The coatings were deposited at substrate bias voltage $-100 \mathrm{~V}$. The AlCrN coating process was carried out at arc current of $80 \mathrm{~A}$ under nitrogen pressure of 1, 2, 3, 4 and $5 \mathrm{~Pa}$. The pressure and gas flow control was carried out with the use of a Baratron capacitance head and MKS flowmeters.

\subsection{Characterization of the Coatings}

The thickness of the coatings was determined by the spherical grinding method (CALOTEST) according to the PNEN ISO 26423:2016-05 standard. The surface roughness measurements were carried out using a Hommel Tester T8000 profilograph.

The coatings were tested using the following test methods:

- X-ray analysis (X'Pert PANalytical, $\mathrm{CuK} \alpha$ radiation)_phase composition of the coatings. The following parameters in XRD measurements were applied: the operating voltage $-40 \mathrm{kV}$, current $-35 \mathrm{~mA}$, scanning speed $-20 \mathrm{~s} / \mathrm{step}$, step -0.05 and $2 \Theta$ range $-20-90^{\circ}$,

- Scanning microscopy (Jeol JSM5500)—coating morphology,

- Energy-dispersive x-ray spectroscopy (Oxford LINK ISIS 300 system)—chemical composition,

- Optical microscopy (Nikon Eclipse MA200) - morphology and thickness of the coatings, evaluation of the damages in the Daimler-Benz test,

- The hardness (Fischerscope ${ }^{\circledR}$ HM2000)-indentation depth fixed at about $0.2 \mu \mathrm{m}$, the value lower than $10 \%$ of the coating thickness for reducing the effect of the substrate. Due to coating hardness, the load ranged from 30 to $40 \mathrm{mN}$,

- Adhesion (Revetest Scratch tester CSEM)-diamond indenter Rockwell C type (tip radius $200 \mathrm{~nm}$ ) moving at a rate of $10 \mathrm{~mm} / \mathrm{min}$, change the linear force from 0 to $200 \mathrm{~N}$ at a speed of $100 \mathrm{~N} / \mathrm{min}$. The critical load $\mathrm{Lc}_{1}$ is defined as the load at which the first coating cracks appear, while the critical load $\mathrm{Lc}_{2}$ is the load at which the complete delamination of the coating from the substrate occurs. The forces were determined as an average of at least three measurements. The Daimler-Benz test was also applied to assess the type and size of the damage of the coating near the indentation formed as a result of Rockwell indentation force of about $1500 \mathrm{~N}$ (Ref 32), 
- The wear (pin-on-disk); normal load-20 N, sliding distance-2000 m, sliding speed- $0.2 \mathrm{~m} / \mathrm{s}$, counterpart $-\mathrm{Al}_{2} \mathrm{O}_{3}$ ball with $10 \mathrm{~mm}$ in diameter, dry sliding. The wear rate $k_{\mathrm{v}}$ was calculated as a ratio of the material volume $V$ removed during the friction test divided by the product of the normal load $L$ and the sliding distance $s$, $k_{\mathrm{v}}=V^{1} L^{-1} s^{-1}$ (Ref 33). The wear volume was estimated from the sectional area of wear $S$ (made perpendicular to wear track) in the coating and the perimeter of wear track. The area of five randomly chosen wear profiles was averaged.

\section{Results and Discussion}

The coatings were deposited using $\mathrm{Ar}_{80} \mathrm{Cr}_{20}$ cathode. Dependent on the pressure of nitrogen, their thickness ranged from 3.5 to $4.5 \mu \mathrm{m}$. With the nitrogen pressure, the coating deposition rate increases to about $36 \mathrm{~nm} / \mathrm{min}$ (at $3 \mathrm{~Pa}$ ) and then decreases, as shown in Fig. 1. This difference in the deposition rate can be caused by the resputtering phenomenon (Ref 34). The effect of this phenomenon can be significant due to the relatively high substrate bias voltage $-100 \mathrm{~V}$. An increase in nitrogen pressure may result in two competing mechanisms. First, the amount of nitrogen ions taking part in the coating formation increases (the deposition rate increases). Secondly, as a result of the increased number of collisions, typical for high nitrogen pressure, ion mobility is reduced, therefore the number and kinetic energy of the species approaching the substrate is significantly reduced. It may cause a decrease in the coating deposition rate. This effect had previously been observed (Ref 30).

Another explanation can be related to target poisoning (Ref 34). AlN phase decomposes at $3000{ }^{\circ} \mathrm{C}$. This temperature is significantly higher than the melting point of the $\mathrm{Cr}\left(1870{ }^{\circ} \mathrm{C}\right)$. It means that aluminum nitride phase forms on the top of the $\mathrm{AlCr}$ target which reduces the sputter rate and the thickness of coatings decreases with increasing nitrogen pressure (Ref 18).

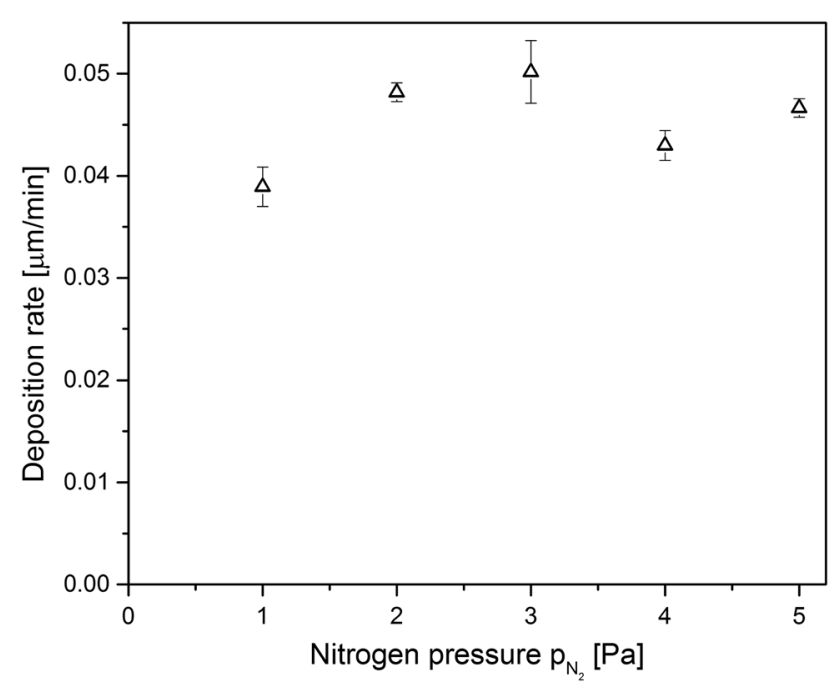

Fig. 1 AlCrN coating deposition rate dependent on nitrogen pressure
The higher values of the deposition rate are probably related to the other chemical composition of the cathode applied and the technological parameters of the coating deposition. Wang et al. (Ref 13) applied the cathode $\mathrm{AlCr}$ with composition 67:33. The results of our tests of AlCrN coatings indicate that the composition of the cathode has a decisive influence on the thickness of the coating (deposition rate).

EDX investigations of the coatings show the presence of nitrogen, aluminum and chromium, and about 0.5 at.\% of oxygen. The occurrence of oxygen is an unintentional effect of the coating deposition technique-cathodic arc evaporation. Analysis of the chemical composition of coatings (Fig. 2) indicates that an increase in nitrogen pressure from 1 to $5 \mathrm{~Pa}$ during deposition results in increase in the concentration of nitrogen in the coating by about 1 at.\%. Simultaneously there is a change in the concentration of the metallic elements of the coating, a reduction in the aluminum concentration by about 2 at. $\%$ and increase in chromium concentration by about 1 at. $\%$

The EDX method does not provide sufficient accuracy for light elements such as oxygen, nitrogen or carbon, therefore the ratio of aluminum to the sum of metallic elements $(\mathrm{Al}+\mathrm{Cr})$ in the coating was determined. The ratio $\mathrm{Al} /(\mathrm{Al}+\mathrm{Cr})$ differs slightly from the composition of the cathode (80:20) and indicates generally the loss of aluminum in the coating with the increase in nitrogen pressure during the process of the coating synthesizing, as has been demonstrated previously (Ref 18, 28). This is probably related to the lower atomic mass of aluminum, which may cause a greater dispersion of aluminum ions compared to chromium in collisions with nitrogen ions and leads to lower condensation of aluminum on the substrate.

In Fig. 3, the XRD diffraction patterns of AlCrN coatings formed at various nitrogen pressures are shown. The diffraction lines from the hexagonal AIN ( $h$-AlN) phase (ICDD 25-1133) and the cubic $\mathrm{CrN}(c-\mathrm{CrN})$ phase (ICDD 11-0065) have been observed. There is also a single diffraction line from the hexagonal $\mathrm{Cr}_{2} \mathrm{~N}$ phase (ICDD 35-0803). Its intensity decreases with the nitrogen pressure during the coating deposition. Careful observation shows that the diffraction lines of $h$-AlN phase are shifted toward lower angles and from $c-\mathrm{CrN}$ phase

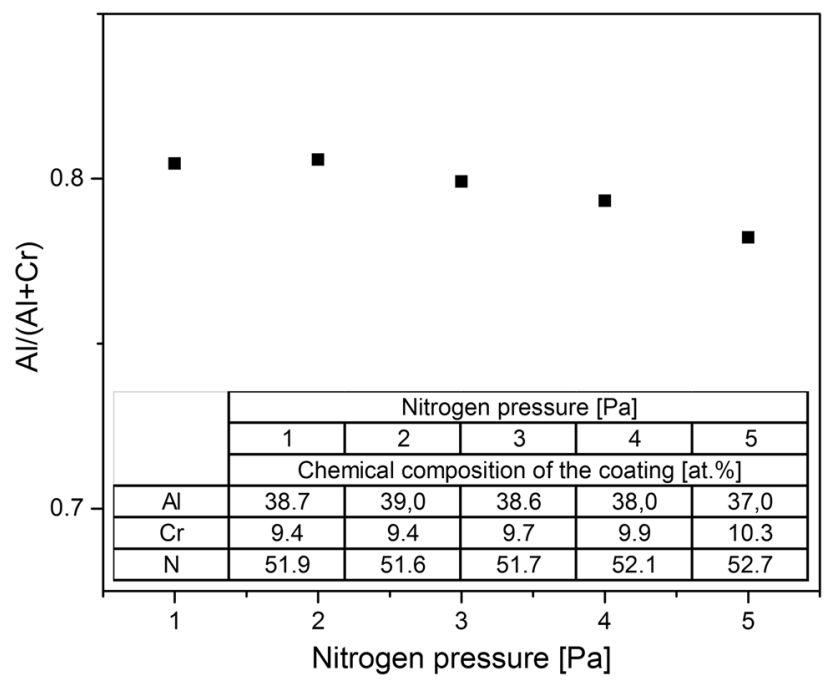

Fig. 2 The chemical composition of AlCrN coatings formed at various nitrogen pressures and the change in the aluminum rate $\mathrm{Al} /$ $(\mathrm{Al}+\mathrm{Cr})$ in the coatings 


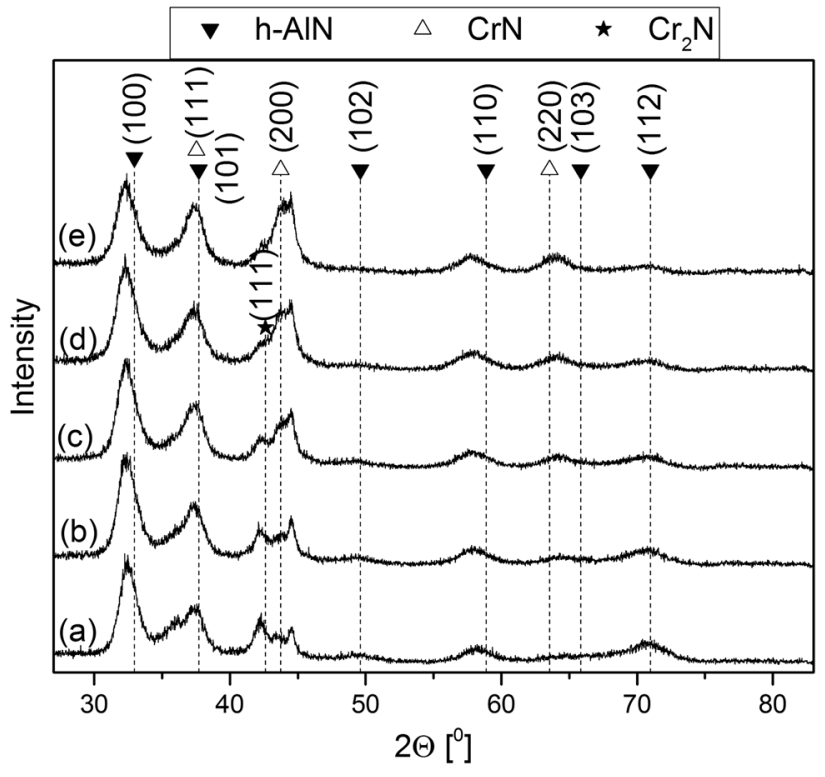

Fig. 3 Diffraction patterns of $\mathrm{AlCrN}$ coatings deposited substrate bias voltage of $-100 \mathrm{~V}$ and nitrogen pressure of: (a) $1 \mathrm{~Pa}$, (b) $2 \mathrm{~Pa}$, (c) $3 \mathrm{~Pa}$, (d) $4 \mathrm{~Pa},(\mathrm{e}) 5 \mathrm{~Pa}$

toward higher angles. The shift of diffraction lines toward higher angles compared to standard positions in $\mathrm{CrN}$ probably results from the substitution of $\mathrm{Cr}$ atoms by $\mathrm{Al}$ atoms with a smaller atomic radius. It is related to relaxation of residual stress caused by the formation of the $h$-AlN phase (Ref 35). A similar effect had formerly been observed (Ref 36). The intensity of the diffraction lines is essentially unchanged with the increase in nitrogen pressure.

In Fig. 4 on the left side, the SEM images of $\mathrm{AlCrN}$ coatings synthesized at various nitrogen pressures are shown. A large number of macroparticles with dimensions reaching even $10 \mu \mathrm{m}$ and chemical composition similar to the composition of the cathode are visible. They are typical defects associated with the technology of coatings deposition applied - cathodic arc evaporation. The macroparticles are loosely bound to the surface of the coating and significantly affect the mechanical properties of the coatings. Microdroplets of cathode material usually with a diameter of a few micrometers are emitted from cathode spots. The collisions between atoms or ions, as a result of high pressure, promote the formation of agglomerates even before depositing on the substrate (Ref 34). It was found that the number and size of macroparticles decreased on the surface of coatings formed at higher pressures.

Wan et al. (Ref 34) observed a small increase in the number and size of macroparticles on the surface of $\mathrm{CrN}$ coatings obtained in the nitrogen pressure ranged from 0.4 to $2.0 \mathrm{~Pa}$. They also found that, irrespective of the pressure, macroparticles with small sizes, up to $0.3 \mu \mathrm{m}$, are the most numerous, and their number increases with nitrogen pressure during the coating deposition. Wang et al. (Ref 13) investigated the effect of AlCrN coating deposition parameters by ion plating method on surface quality. They found that in the range of nitrogen pressures from 1 to $2 \mathrm{~Pa}$, the number of macroparticles on the surface of the coatings increases and their average diameter is from about 0.5 to about $0.64 \mu \mathrm{m}$.

The SEM fracture cross-section images of AlCrN coatings deposited at different nitrogen pressure are shown in Fig. 4, on the right side. The coatings present a compact dense structure, without any visible delamination or defects. One of the features of the cathodic arc evaporation processes is the high ionization rate during coating deposition. Additionally, relatively high substrate bias voltage leads to strong ion bombardment of the substrate and in consequence to dense coating structure.

Wang et al. (Ref 16) found that in coatings formed using magnetron sputtering columnar grains with width of $60 \mathrm{~nm}$ are observed. The large gaps between the columns related to defects with coating growth are the reason of low hardness, about $10 \mathrm{GPa}$.

The $\mathrm{Ra}$ and $\mathrm{Rz}$ roughness parameters of coatings deposited at various nitrogen pressure are presented in Fig. 5. The Ra parameter is about 8-10 times smaller than the Rz parameter. Both parameters decrease monotonically with the increase in nitrogen pressure. All coatings were characterized by a relatively high roughness related to the occurrence of macroparticles on the surface. This effect is typical for the method of coating formation - cathodic arc evaporation (Ref 37).

The highest value of $\mathrm{Ra}$ and $\mathrm{Rz}$ parameters were recorded for coatings formed in a nitrogen atmosphere of $1 \mathrm{~Pa}, 0.27 \mu \mathrm{m}$ and $2.1 \mu \mathrm{m}$ respectively. AlCrN coatings obtained by cathodic arc evaporation are characterized by a relatively large roughness parameter $\mathrm{Ra}$ of about $0.3 \mu \mathrm{m}$ (Ref 22), higher than for CrN coatings, about 0.05-0.09 $\mu \mathrm{m}$ dependent on the deposition conditions (Ref 38). Creasey et al. (Ref 39, 40) found that the amount and dimensions of macroparticles on the surface of the substrate depend on the melting point of the cathode. The lower the temperature of the cathode, the larger the linear dimensions of the deposited particles and the greater the number of particles deposited. In case of $\mathrm{Al}$ and $\mathrm{Cr}$, the maximum dimensions of deposited particles are $10-20 \mu \mathrm{m}$ and $1 \mu \mathrm{m}$, respectively.

The requirement for the correct hardness measurement of the coatings with a thickness of a few micrometers is the selection of a suitable depth of penetration indenter no larger than $1 / 10$ of the thickness of the coating to eliminate the interaction of the substrate. For coating thicknesses in the range from 3.5 to $4.5 \mu \mathrm{m}$, the indentation depth would be slightly higher than the Ra roughness parameter. However, it is known that the indentation depth should not be less than $20 \times \mathrm{Ra}$. Therefore, the method described by Romero et al. (Ref 28) was applied. The rough coatings were polished using fine-grained $(2 \mu \mathrm{m})$ diamond powder. After this operation, significantly reducing the surface roughness of the coating (up to about $0.05 \mu \mathrm{m}$ ), the hardness was determined with much lower measurement uncertainty. During polishing, the thickness decreased by about 0.1 to $0.2 \mu \mathrm{m}$. This slight reduction in thickness did not affect the hardness measurement.

The results of hardness for $\mathrm{AlCrN}$ coatings deposited at various nitrogen pressures are shown in Fig. 6. The minimum hardness, below $16 \mathrm{GPa}$, is visible for the coating deposited at nitrogen pressure of $3 \mathrm{~Pa}$. However, taking into account the measurement uncertainty, it can be assumed that all coatings, regardless of nitrogen pressure during deposition, are characterized by similar hardness and Young's modulus.

Relatively low hardness of AlCrN coatings obtained at a nitrogen pressure from 1 to $3 \mathrm{~Pa}$ is related to the presence of the $\alpha-\mathrm{Cr}$ phase (Fig. 3), characterized by low hardness, in the mixture of $\alpha-\mathrm{Cr}$ and the hexagonal phase of $\mathrm{Cr}_{2} \mathrm{~N}$. The increase in nitrogen pressure favors the formation of a cubic $\mathrm{CrN}$ phase (Ref 41).

AlCrN coatings with $\mathrm{Al}$ content of up to $75 \%$ are characterized by hardness in the range of 28-40 GPa (Ref 8, 

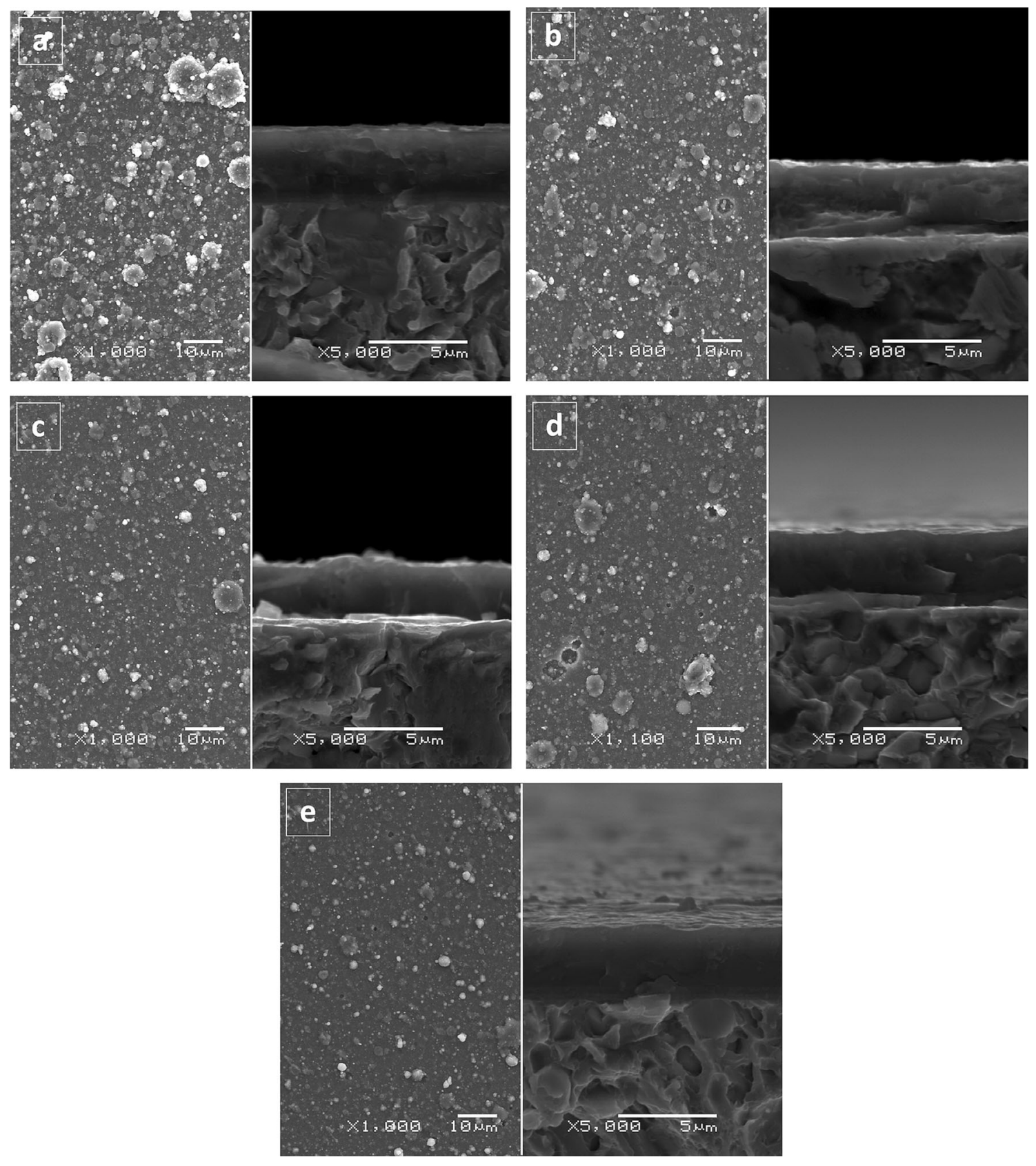

Fig. 4 SEM surface images of AlCrN coatings deposited at nitrogen pressure: (a) $1 \mathrm{~Pa}$, (b) $2 \mathrm{~Pa}$, (c) $3 \mathrm{~Pa}$, (d) $4 \mathrm{~Pa}$, (e) $5 \mathrm{~Pa}$

22, 42). It depends on the deposition conditions and chemical composition of the coating. Hirai et al. (Ref 42) found that the hardness of pulsed laser deposited $(\mathrm{Cr} 1-x, \mathrm{Al} x) \mathrm{N}$ coatings increases monotonically from 2300 to $2900 \mathrm{HV}$ ( $x$ about $75 \%$ ), and then decreases rapidly to $1100 \mathrm{HV}(x=1)$. The hardness of $\mathrm{AlCrN}$ coating with about $90 \% \mathrm{Al}$ is about $1500 \mathrm{HV}$. Reiter et al. (Ref 8) confirmed the above statements for coatings formed in the reactive cathodic arc processes. Wang et al. (Ref 16) investigated the influence of bias voltage on the hardness of CrAlN coatings deposited by magnetron sputtering. They found that $\mathrm{Al}_{0.40} \mathrm{Cr}_{0.60} \mathrm{~N}$ coatings deposited at negative substrate bias voltage of 50 and $160 \mathrm{~V}$ are characterized by relatively low hardness 10.4 and $12.7 \mathrm{GPa}$, respectively. The coating hardness increases to $25.5 \mathrm{GPa}$ at bias of $-260 \mathrm{~V}$. Such low hardness results mainly from large grains and less compact microstructure with a large number of defects. The crystallite size decreases from $52(-50 \mathrm{~V})$ to $13 \mathrm{~nm}(-260 \mathrm{~V})$. This reduction in the crystallite size, according to the Halle-Petch relationship, is the reason for the increase in hardness. Reduction of the crystallite size leads to an increase in the grain boundary fraction. It also limits the possibility of lattice dislocations movement, which leads to the strength enhancement (Ref 16).

Equally low hardness from 6 to $14 \mathrm{GPa}$ of AlCrN coatings deposited by reactive magnetron co-sputtering using a direct current (DC) power source to Al target and a radio frequency (RF) power source to $\mathrm{Cr}$ target is presented by Wang et al. (Ref 18). It is related to the sharply quadrangular prism shape grains of the coating with a size of about $60-70 \mathrm{~nm}$ and the porous surface of the coating. Wuhrer and Yeung (Ref 30) found that 


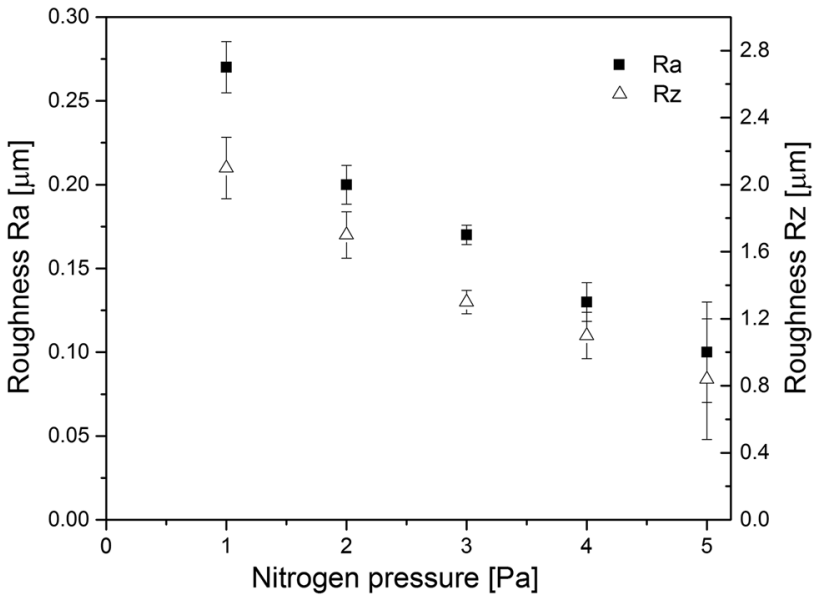

Fig. 5 Roughness parameters $\mathrm{Ra}$ and $\mathrm{Rz}$ of $\mathrm{AlCrN}$ coatings deposited at different nitrogen pressure

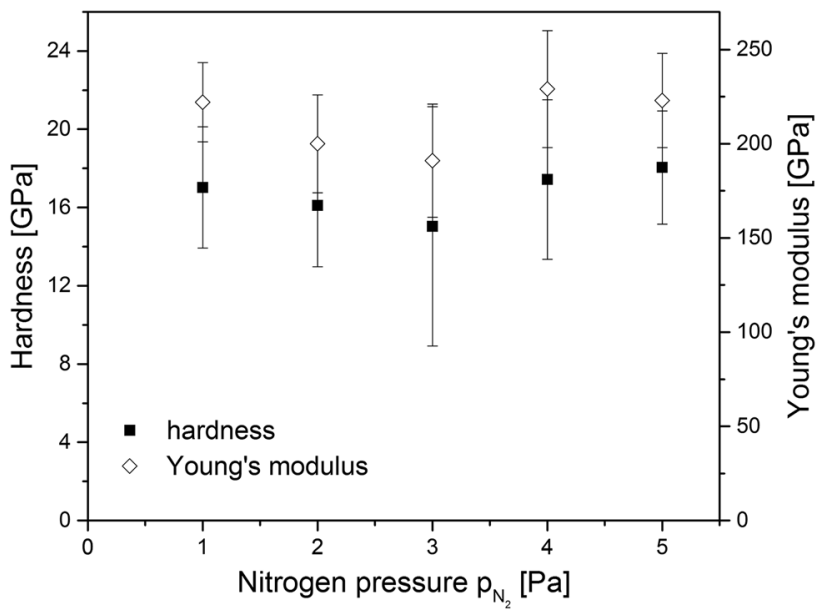

Fig. 6 Hardness of AlCrN coatings deposited at different nitrogen pressure

the hardness of $\mathrm{AlCrN}$ coatings deposited by magnetron sputtering decreases from about 2850 to $1900 \mathrm{HV}$ with nitrogen pressure increase from 0.05 to $0.32 \mathrm{~Pa}$. This is associated with a significant reduction in the concentration of aluminum in the coating.

It should also be noted that higher hardness of the coatings with lower aluminum concentration is related to density of the coatings. The coatings with $c$-AlN should have higher hardness than $h$-AlN due to their higher volume density $(\sim 18 \%)$ compared with that of $h$-AlN (Ref 43).

Adhesion of the coating, except hardness, is one of its most important properties. From among many different methods for its determination, the scratch test is probably the most commonly used one. It is determined by unique numerical result. A significant influence on the determined adhesion of the coating is, among others, the hardness of the substrate and its roughness. It was found that with the increase in the substrate roughness parameter $\mathrm{Ra}$, the critical load $\mathrm{Lc}_{2}$ of the coating decreases (Ref 44, 45). In turn, the increase in the hardness of the substrate causes an increase in the measured critical load $\mathrm{Lc}_{2}$ (Ref 45). Therefore, special attention was paid to the preparation of substrates, they were characterized by the same hardness and roughness.

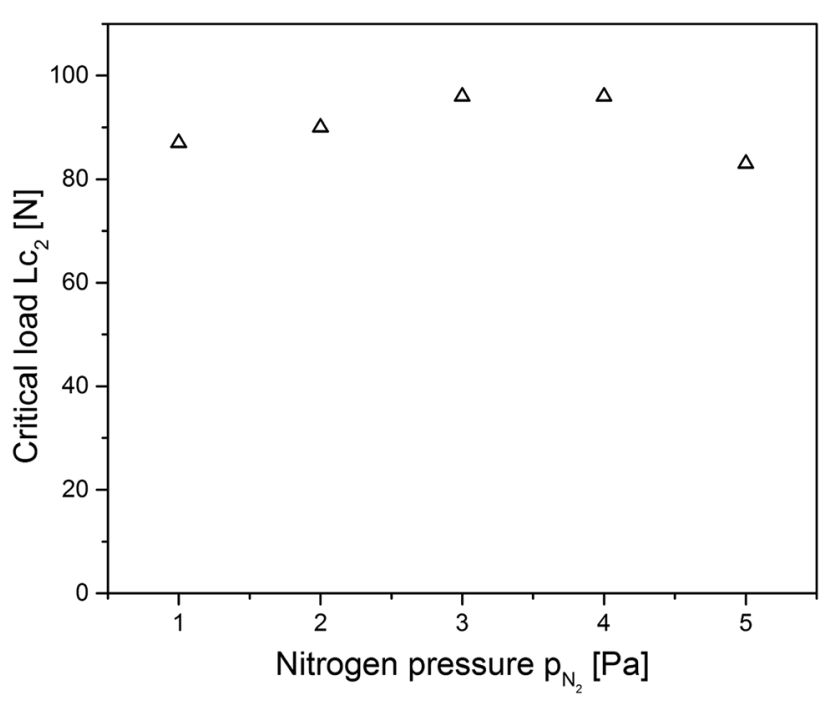

Fig. 7 Critical load $\mathrm{Lc}_{2}$ of $\mathrm{AlCrN}$ coatings deposited using different nitrogen pressure

The essence of the scratch test is to introduce stresses by deforming the surface of the coating with an indenter moving simultaneously in two directions: perpendicular and parallel to the surface. The critical load $\mathrm{Lc}_{2}$ of coatings deposited in different nitrogen pressure is shown in Fig. 7. The highest critical load, about $95 \mathrm{~N}$, was observed for coatings formed in an atmosphere with nitrogen pressure 3 and $4 \mathrm{~Pa}$. The coatings formed at other nitrogen pressure show a lower critical force, $83 \mathrm{~N}(5 \mathrm{~Pa})$ or $87 \mathrm{~N}(1 \mathrm{~Pa})$. Slightly lower values, around $70 \mathrm{~N}$, were presented for the AlCrN coating deposited from the $\mathrm{Al}_{67} \mathrm{Cr}_{33}$ target to the cemented carbide substrate $(\mathrm{WC}+10$ at.\% Co) by cathodic arc evaporation (Ref 22). The better adhesion, $70-90 \mathrm{~N}$, is characterized by the AlTiN coatings formed on a high-speed steel substrate by the arc evaporation method from $\mathrm{Ti}_{67} \mathrm{Cr}_{33}$ cathode (Ref 46). Significantly lower $\mathrm{Lc}_{2}$ values (approximately $19 \mathrm{~N}$ ) were observed for the $\mathrm{AlCrN}$ coating deposited using $\mathrm{Al}_{70} \mathrm{Cr}_{30}$ cathode on 4140 steel (42CrMo4) ( $\mathrm{Ref} 47)$. CrN coatings on this steel are characterized by higher adhesion-around $40 \mathrm{~N}$ (Ref 48).

The Daimler-Benz indentation test results are presented in Fig. 8. The micrographs of AlCrN coating show generally the only small chipping for all coatings. These results confirm scratch test results where $\mathrm{Lc}_{2}$ is almost constant independent on nitrogen pressure during deposition. The coatings are characterized by small circular cracks around the indentation, as shown in Fig. 8(a), (b), (d) and (e). They probably correspond to the generation of large tensile stress resulted in the pileup of the substrate material around the indentation in the DB test. This effect dominates in the hard and brittle coatings (Ref 41).

Adhesion of the coatings expressed as critical force in the scratch test depends on many factors, including the roughness and hardness of the substrate. Valleti et al. (Ref 45) found that in the case of substrates with increased hardness the higher critical force has been recorded. Due to it, the roughness of the substrates was the same.

The highest coefficient of friction around 0.7 corresponds to the coating deposited under nitrogen pressure of $1 \mathrm{~Pa}$. It slightly decreases to 0.6 for the coating deposited at $4 \mathrm{~Pa}$. Due to measurement uncertainty of about 0.07 coefficient of friction rather do not depend on nitrogen pressure and substrate bias voltage during deposition. Similar conclusion is presented by 

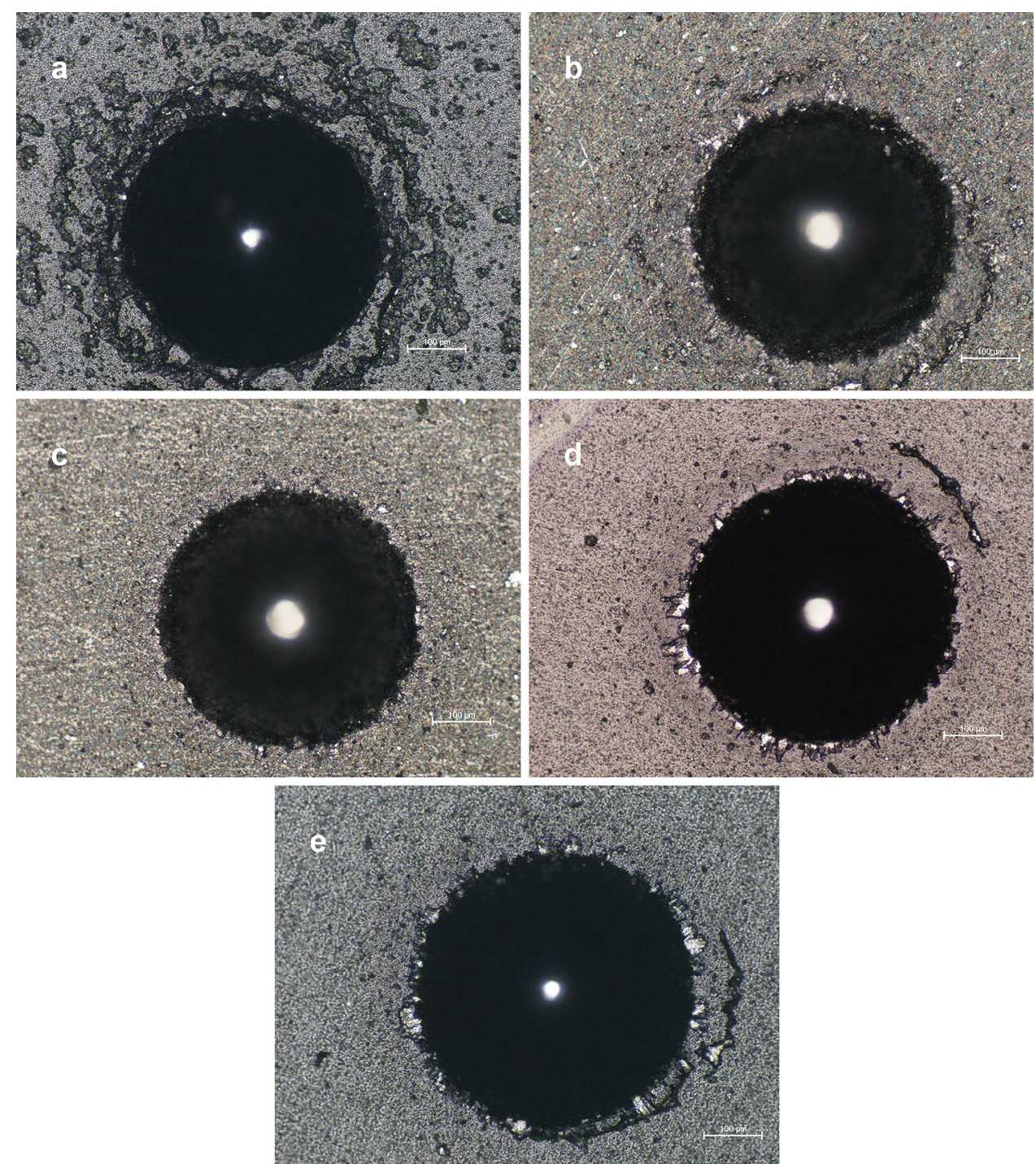

Fig. 8 The Daimler-Benz indentation results of AlCrN coatings deposited at nitrogen pressure of: (a) $1 \mathrm{~Pa}$, (b) $2 \mathrm{~Pa}$, (c) $3 \mathrm{~Pa}$, (d) $4 \mathrm{~Pa}$, and (e) $5 \mathrm{~Pa}$

Romero et al. (Ref 28). Similar value of coefficient of friction (0.75) was found by Mo and $\mathrm{Zhu}(\mathrm{Ref} 49)$ for $\mathrm{Al}_{70} \mathrm{Cr}_{30}$ coating deposited by the multi-arc ion plating technique. Antonov et al. (Ref 26) found that applying $\mathrm{Al}_{2} \mathrm{O}_{3}$ as a counterpart, in wide range of sliding speed, from 0.002 to $1.458 \mathrm{~m} / \mathrm{s}$ coefficient if friction is constant, about 0.65 .

The SEM morphology of selected coating wear tracks is presented in Fig. 9. The sliding distance in wear test was $2000 \mathrm{~m}$. The worn track in the coatings deposited at nitrogen pressure of $1 \mathrm{~Pa}$ is rough and exhibits extensive abrasive wear. In wear test of other coatings, a smooth worn surface was formed. Some holes in the wear track related to macroparticles removed during the test are also observed. The coatings deposited at nitrogen pressure of 4 and $5 \mathrm{~Pa}$ show smooth surface without plowing and debris. The wear depth was about $2 \mu \mathrm{m}(1 \mathrm{~Pa})$ and decreases with nitrogen pressure to about $0.6 \mu \mathrm{m}(4 \mathrm{~Pa})$.

EDX analysis of wear tracks reveals the next element on the worn surface-oxygen. Its concentration decreases with nitrogen pressure during deposition. The aluminum rate $\mathrm{Al} /(\mathrm{Al}+$ $\mathrm{Cr})$ in the wear track is similar as in corresponding coatings.
The sliding speed and the normal load are two key parameters in wear test. They also have a great influence on the temperature at the contact area during wear sliding. The flash temperature at the contact area can be expressed by the following equations (Ref 50$)$ :

$$
\begin{aligned}
\Delta T & =\frac{\mu P v}{4\left(K_{1}+K_{2}\right) \alpha}, \\
\alpha & =\left(\frac{P}{\pi H}\right)^{\frac{1}{2}},
\end{aligned}
$$

where: $\Delta T$ - the flash temperature at the contact area, $\mu$ - the friction coefficient, $P$ - the normal load, $v$ - the sliding speed, $\alpha$ - the contact radius of the real contact area, $H$ - the hardness of the coating, $K_{1}$ and $K_{2}$ - the thermal conductivities of the coating $\left[5 \mathrm{~W} \mathrm{~m}^{-1} \mathrm{~K}^{-1}\right.$ (Ref 51)] and the $\mathrm{Al}_{2} \mathrm{O}_{3}$ counterpart [34 $\mathrm{W} \mathrm{m}^{-1} \mathrm{~K}^{-1}$ (Ref 52)].

The calculations of flash temperature indicate that it is about $800 \mathrm{~K}$. Due to high hardness standard deviation, the flash temperature ranges from 600 to $1000 \mathrm{~K}$. During dry wear process the surface oxidation can proceed and $\mathrm{Al}_{2} \mathrm{O}_{3}$ protective 

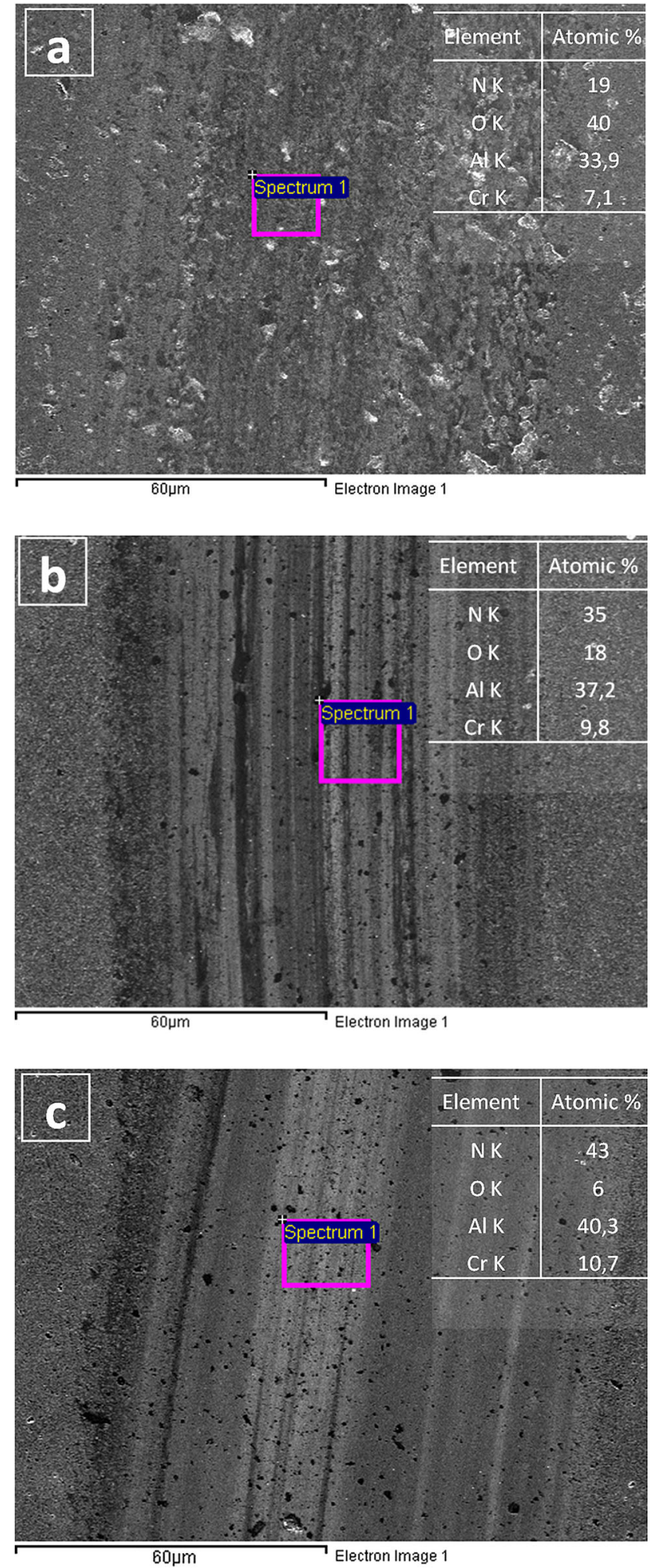

Fig. 9 SEM micrographs and chemical composition from EDX of the wear tracks obtained after ball-on-disk test at AlCrN coatings deposited at nitrogen pressure of: (a) $1 \mathrm{~Pa}$, (b) $3 \mathrm{~Pa}$, (c) $5 \mathrm{~Pa}$

surface films can be formed. The oxidation behavior of CrAlN is mainly controlled by the $\mathrm{Al}$ present in the coating ( $\operatorname{Ref} 15)$. Over a wide temperature range, $\mathrm{Al}_{2} \mathrm{O}_{3} \quad\left(\Delta G^{\circ}=\right.$ - $378.2 \mathrm{kcal} / \mathrm{mol})$ is much more stable than $\mathrm{Cr}_{2} \mathrm{O}_{3}\left(\Delta G^{\circ}=\right.$ - $252.9 \mathrm{kcal} / \mathrm{mol})(\operatorname{Ref} 10)$.

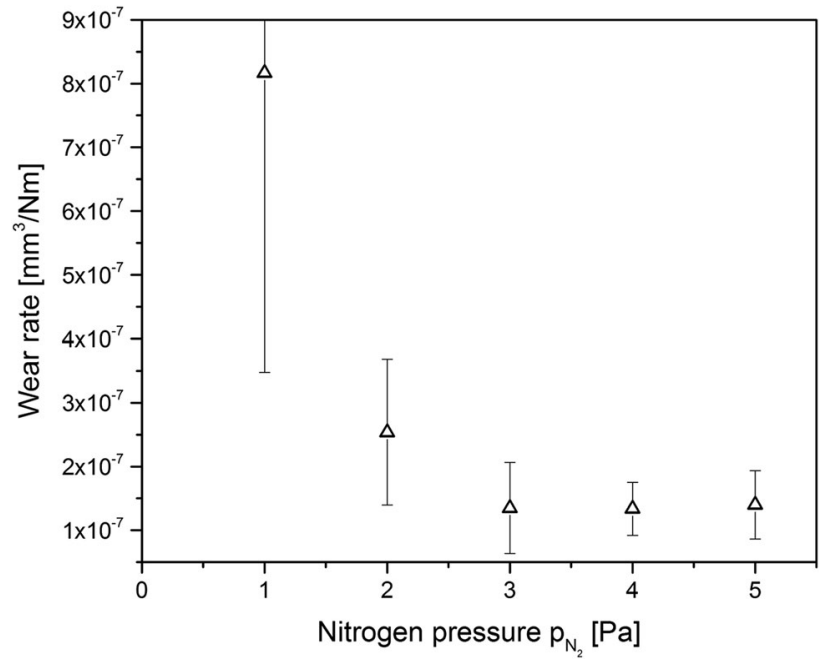

Fig. 10 Wear rate of $\mathrm{AlCrN}$ coatings deposited at constant negative substrate bias voltage of $100 \mathrm{~V}$ and different nitrogen pressure

Figure 10 presents the wear rate calculated from the normal load, sliding distance and the wear volume. The highest wear rate, about $8.2 \times 10^{-7} \mathrm{~mm}^{3} / \mathrm{Nm}$, is for the coating deposited at nitrogen pressure of $1 \mathrm{~Pa}$. The specific wear rate corresponds to previously found values $(\operatorname{Ref} 8,28,53,54)$. The wear of $\mathrm{AlCrN}$ depends on chemical composition of the coatings $(\operatorname{Ref} 8)$. The lowest wear rate calculated from ball cratering, about $2 \times 10^{-15} \mathrm{~m}^{3} / \mathrm{Nm}$, was found for $\mathrm{Al}_{71} \mathrm{Cr}_{29} \mathrm{~N}$ coating (Ref 8). In this wear tests, the hardened steel ball (diameter $30 \mathrm{~mm}$ ) loaded with $0.54 \mathrm{~N}$ was applied. Simultaneously the drilling tests performed on the $\mathrm{X} 210 \mathrm{Cr} 12$ steel confirmed the highest tool life for such coating (Ref 8). One of the worse wear rates was found by Liu et al. (Ref 53) for $\mathrm{Al}_{66} \mathrm{Cr}_{34} \mathrm{~N}$ coating. In this case, the couterbody in ball-on-disk test was $\mathrm{SiC}$ ball with $9.525 \mathrm{~mm}$ in diameter. Lin et al. (Ref 54) found the wear rate ranged from about $3.4 \times 10^{-6}$ to $16 \times 10^{-6} \mathrm{~mm}^{3} / \mathrm{Nm}$ for $\mathrm{Cr}_{77} \mathrm{Al}_{23} \mathrm{~N}$ coatings deposited by pulsed-closed field unbalanced magnetron sputtering. The wear rate dependents on substrate to chamber wall distance. The investigations of Romero et al. (Ref 28) show that the wear rate of $\mathrm{Cr}_{60} \mathrm{Al}_{40} \mathrm{~N}$ coatings deposited by cathodic arc evaporation at different bias voltage is about $2 \times 10^{-16} \mathrm{~m}^{3} / \mathrm{Nm}$ and is independent on substrate bias voltage and type of counterpart.

The type of counterpart and sliding speed can have a great influence on wear process. The AlCrN coating wear rate in relation to $\mathrm{Al}_{2} \mathrm{O}_{3}$ counterpart ranges from $3 \times 10^{-6}$ to $2 \times 10^{-7} \mathrm{~mm}^{3} / \mathrm{Nm}$ at sliding speed of $0.16 \mathrm{~m} / \mathrm{s}$. About one level higher values of wear rate were calculated for $\mathrm{ZrO}_{2}$ and $\mathrm{Si}_{3} \mathrm{~N}_{4}$ counterparts, from $9 \times 10^{-5}$ to $5 \times 10^{-6} \mathrm{~mm}^{3} / \mathrm{Nm}$ (Ref 26).

CrN coating tested under the same conditions shows the coefficient of friction of about 0.8 and the depth of wear track about $0.3 \mu \mathrm{m}$. It seems that wear rate depends on deposition method, deposition parameters, chemical composition of the coatings and selected testing method.

Despite high hardness, about $35 \mathrm{GPa}, \mathrm{Al}_{70} \mathrm{Cr}_{30} \mathrm{~N}$ coating deposited using cathodic arc evaporation at nitrogen pressure of 3.2 $\mathrm{Pa}$ and substrate temperature and substrate bias voltage of about $300{ }^{\circ} \mathrm{C}$ and $-120 \mathrm{~V}$, respectively, shows coefficient of friction of 0.68 and wear rate of about $6 \times 10^{-7} \mathrm{~mm}^{3} / \mathrm{Nm}$ (Ref $55)$. 
Lower coefficient of friction, about $0.51 \pm 0.02$ and specific wear rate $(5.7 \pm 0.8) \times 10^{-7} \mathrm{~mm}^{3} / \mathrm{Nm}$ was found for CrN coating deposited using cathodic arc evaporation (Ref 56). The test conditions were the same as in AlCrN coatings. Really, $\mathrm{Al}$ addition to $\mathrm{CrN}$ improves the wear resistance of the coatings, despite relatively low hardness ranged from 15 to $18 \mathrm{GPa}$. The wear track is smooth indicating on abrasive type of wear.

Many authors indicate that for AlCrN coatings with hexagonal phase of AIN the mechanical properties are deteriorated (Ref 8, 42, 43, 57). Indeed, hardness in investigated coatings is lower for about $50-100 \%$ compared to coatings with cubic AlN phase (Ref 9, 29). Despite it, the adhesion of the coatings is high, above $80 \mathrm{~N}$ and wear rate is low, about $1.4 \times 10^{-7} \mathrm{~mm}^{3} / \mathrm{Nm}$ for coatings deposited at nitrogen pressure higher than $2 \mathrm{~Pa}$. It means that coatings show very good tribological properties.

In coatings deposited at 1-2 $\mathrm{Pa}$ of nitrogen pressure the diffraction lines from $\mathrm{Cr}_{2} \mathrm{~N}$ and $\mathrm{Cr}$ phases are observed, as shown in Fig. 3. It is known that $\mathrm{Cr}_{2} \mathrm{~N}$ has higher hardness, lower adhesion and worse tribological properties, higher coefficient of friction and wear rate than $\mathrm{CrN}$ (Ref 41). For higher nitrogen pressure $\mathrm{Cr}_{2} \mathrm{~N}$ phase is not observed, the critical load increases and wear rate decreases. SEM studies indicate that the dominating wear mechanism in the tests against $\mathrm{Al}_{2} \mathrm{O}_{3}$ ball is abrasion.

\section{Conclusions}

The paper presents the results of investigations of $\mathrm{AlCrN}$ coatings deposited using cathodic arc evaporation from $\mathrm{Al}_{80} \mathrm{Cr}_{20}$ cathode. The effects of nitrogen pressure and substrate bias voltage on chemical and phase structure as well as mechanical properties were studied and made it possible to formulate the following conclusions:

- The highest deposition rate of coating was observed for nitrogen pressure of $3 \mathrm{~Pa}$, about $50 \mathrm{~nm} / \mathrm{min}$.

- In the coatings occur two phases: hexagonal aluminum nitride and cubic chromium nitride.

- The roughness $\mathrm{Ra}$ of the coating surface decreases from about 0.27 to about $0.10 \mu \mathrm{m}$ with the increase in nitrogen pressure. This is related to the reduction of the amount of macroparticles on the surface of the coating,

- The hardness of the coatings, taking into account the uncertainty of measurement, is independent on the nitrogen pressure and is about $17 \mathrm{GPa}$.

- The coatings deposited at a nitrogen pressure of about 3$4 \mathrm{~Pa}$ are characterized by the highest adhesion to the substrate, the critical force is about $95 \mathrm{~N}$.

- The coatings deposited at nitrogen pressure of 2-5 $\mathrm{Pa}$ are characterized by low wear rate between $1.3 \times 10^{-7}$ and $2.5 \times 10^{-7} \mathrm{~mm}^{3} / \mathrm{Nm}$.

\section{Acknowledgments}

Publication partly financed by the National Centre for Research and Development, Poland, BIOSTRATEG3/344303/14/NCBR/ 2018 .

\section{Open Access}

This article is distributed under the terms of the Creative Commons Attribution 4.0 International License (http://creativeco mmons.org/licenses/by/4.0/), which permits unrestricted use, distribution, and reproduction in any medium, provided you give appropriate credit to the original author(s) and the source, provide a link to the Creative Commons license, and indicate if changes were made.

\section{References}

1. A. Lousa, J. Romero, E. Martínez, J. Esteve, F. Montala, and L. Carreras, Multilayered Chromium/Chromium Nitride Coatings for Use in Pressure Die-Casting, Surf. Coat. Technol., 2001, 146-147, p 268273

2. A. Conde, C. Nanas, A.B. Cristobal, J. Housden, and J. de Damborenea, Characterization of Corrosion and Behaviour of Nanoscaled E-Beam PVD CrN Coatings, Surf. Coat. Technol., 2006, 201, p 2690-2695

3. J. Kamiński, J. Rudnicki, C. Nouveau, A. Savan, and P. Beer, Resistance to Electrochemical Corrosion of CrxNy and DCL-Coated Steel Tools in the Environment of Wet Wood, Surf. Coat. Technol., 2005, 200, p 83-86

4. B. Navinšek, P. Panjan, and I. Milošev, Industrial Applications of $\mathrm{CrN}$ (PVD) Coatings, Deposited at High and Low Temperatures, Surf. Coat. Technol., 1997, 97, p 182-191

5. W. Chen, J. Zheng, X. Meng, S. Kwon, and S. Zhang, Investigation on Microstructures and Mechanical Properties of AlCrN Coatings Deposited on the Surface of Plasma Nitrocarburized Cool-Work Tool Steels, Vacuum, 2015, 121, p 194-201

6. Y. Long, J. Zeng, D. Yu, and S. Wu, Microstructure of TiAlN and CrAlN Coatings and Cutting Performance of Coated Silicon Nitride Inserts in Cast Iron Turning, Ceram. Int., 2014, 40, p 9889-9894

7. M. Michalak, R. Michalczewski, E. Osuch-Słomka, D. MaldonadoCortés, and M. Szczerek, The Effect of Temperature on Wear Mechanism of the AlCrN Coated Components, Key Eng. Mater, 2016, 674, p 233-238

8. A.E. Reiter, V.H. Derflinger, B. Hanselmann, T. Bachmann, and B. Sartory, Investigation of the Properties of $\mathrm{Al}_{1-\mathrm{x}} \mathrm{Cr}_{\mathrm{x}} \mathrm{N}$ Coatings Prepared by Cathodic Arc Evaporation, Surf. Coat. Technol., 2005, 200, p 2114-2122

9. C. Sabitzer, J. Paulitsch, S. Kolozsvári, R. Rachbauer, and P.H. Mayrhofer, Influence of Bias Potential and Layer Arrangement on Structure and Mechanical Properties of Arc Evaporated Al-Cr-N Coatings, Vacuum, 2014, 106, p 49-52

10. H.C. Barshilia, N. Selvakumar, B. Deepthi, and K.S. Rajam, A Comparative Study of Reactive Direct Current Magnetron Sputtered CrAlN and CrN Coatings, Surf. Coat. Technol., 2006, 201, p 21932201

11. J. Lin, B. Mishra, J.J. Moore, and W.D. Sproul, A Study of the Oxidation Behavior of CrN and CrAIN Thin Films in Air Using DSC and TGA Analysis, Surf. Coat. Technol., 2008, 202, p 3272-3283

12. Y.C. Chim, X.Z. Ding, X.T. Zeng, and S. Zhang, Oxidation Resistance of TiN, CrN, TiAlN and CrAlN Coatings Deposited by Lateral Rotating Cathode Arc, Thin Solid Films, 2009, 517, p 4845-4849

13. L. Wang, S. Zhang, Z. Chen, J. Li, and M. Li, Influence of Deposition Parameters on Hard Cr-Al-N Coatings Deposited by Multi-Arc Ion Plating, Appl. Surf. Sci., 2012, 258, p 3629-3636

14. H. Du, L. Wang, M. Young, H. Zhao, J. Xiong, and W. Wan, Structure and Properties of Lanthanum Doped AlCrN Coatings, Surf. Coat. Technol., 2018, 337, p 439-446

15. O. Banakh, P.E. Schmid, R. Sanjines, and F. Levy, High-Temperature Oxidation Resistance of Cr1-xAlxN Thin Films Deposited by Reactive Magnetron Sputtering, Surf. Coat. Technol., 2003, 163-164, p 57-61

16. Y.X. Wang, S. Zhang, J.W. Lee, W.S. Lew, and B. Li, Influence of Bias Voltage on the Hardness and Toughness of CrAlN Coatings Via Magnetron Sputtering, Surf. Coat. Technol., 2012, 206, p 5103-5107

17. Y. Benlatreche, C. Nouveau, I. Rahil, R. Marchal, and L. Chekour, Comparative Studies on Mo-Cr-N and Al-Cr-N Coatings Obtained by 
PVD Dual Magnetron Sputtering, Plasma Process. Polym., 2009, 6, p S135-S140

18. X. Wang, L.S. Wang, Z.B. Qi, G.H. Yue, Y.Z. Chen, Z.C. Wang, and D.L. Peng, Investigation on the Structure and Properties of AlxCr1-xN Coatings Deposited by Reactive Magnetron Co-sputtering, J. Alloys Compd., 2010, 502, p 243-249

19. K. Bobzin, T. Brogelmann, and R.H. Brugnara, Aluminum-Rich HPPMS (Cr1-xAlx)N Coatings Deposited with Different Target Compositions and at Various Pulse Lengths, Vacuum, 2015, 122, p 201-207

20. K. Bobzin, T. Brögelmann, and C. Kalscheuer, Triboactive CrAlN + X Hybrid dcMS/HPPMS PVD Nitride Hard Coatings for Friction and Wear Reduction on Components, Surf. Coat. Technol., 2017, 332, p $452-463$

21. N. Bagcivan, K. Bobzin, G. Grundmeier, M. Wiesing, O. Ozcan, C. Kunze, and R.H. Brugnara, Influence of HPPMS Pulse Length and Inert Gas Mixture on the Properties of $(\mathrm{Cr}, \mathrm{Al}) \mathrm{N}$ Coatings, Thin Solid Films, 2013, 549, p 192-198

22. A.E. Reiter, C. Mitterer, M. Rebelo de Figueiredo, and R. Franz Abrasive and Adhesive Wear Behavior of Arc-Evaporated $\mathrm{Al}_{1-\mathrm{x}} \mathrm{Cr}_{\mathrm{x}} \mathrm{N}$ Hard Coatings, Tribol. Lett., 2010, 37, p 605-611

23. T.S. Kumar, S.B. Prabu, G. Manivasagam, and K.A. Padmanabhan, Comparison of TiAlN, AlCrN, and AlCrN/TiAlN Coatings for CuttingTool Applications, Int. J. Miner. Metall. Mater., 2014, 21(8), p 796-804

24. W. Chen, J. Zheng, X. Meng, S. Kwon, and S. Zhang, Investigation on Microstructures and Mechanical Properties of $\mathrm{AlCrN}$ Coatings Deposited on the Surface of Plasma Nitrocarburized Cool-Work Tool Steels, Vacuum, 2015, 121, p 194-201

25. W. Chen, J. Zheng, Y. Lin, S. Kwon, and S. Zhang, Comparison of AlCrN and AlCrTiSiN Coatings Deposited on the Surface of Plasma Nitrocarburized High Carbon Steels, Appl. Surf. Sci., 2015, 332, p 525-532

26. M. Antonov, H. Afshari, J. Baronins, E. Adoberg, T. Raadik, and I. Hussainova, The Effect of Temperature and Sliding Speed on Friction and Wear of $\mathrm{Si}_{3} \mathrm{~N}_{4}, \mathrm{Al}_{2} \mathrm{O}_{3}$, and $\mathrm{ZrO}_{2}$ Balls Tested Against AlCrN PVD Coating, Tribol. Int., 2018, 118, p 500-514

27. G.S. Kim and S.Y. Lee, Microstructure and Mechanical Properties of AlCrN Films Deposited by CFUBMS, Surf. Coat. Technol., 2006, 201, p 4361-4366

28. J. Romero, M.A. Gómez, J. Esteve, F. Montalà, L. Carreras, M. Grifol, and A. Lousa, CrAlN Coatings Deposited by Cathodic Arc Evaporation at Different Substrate Bias, Thin Solid Films, 2006, 515, p 113 117

29. T. Polcar and A. Cavaleiro, High-Temperature Tribological Properties of CrAlN, CrAlSiN and AlCrSiN Coatings, Surf. Coat. Technol., 2011, 206, p 1244-1251

30. R. Wuhrer and W.Y. Yeung, A Comparative Study of Magnetron Cosputtered Nanocrystalline Titanium Aluminium and Chromium Aluminium Nitride Coatings, Scr. Mater., 2004, 50, p 1461-1466

31. V.D. Ovcharenko, A.S. Kuprin, G.N. Tolmachova, I.V. Kolodiy, A. Gilewicz, O. Lupicka, J. Rochowicz, and B. Warcholinski, Deposition of Chromium Nitride Coatings Using Vacuum Arc Plasma in Increased Negative Substrate Bias Voltage, Vacuum, 2015, 117, p 27-34

32. Verein-Deutscher-Ingenieure Normen, VDI, 3198, VDI-Verlag, Dusseldorf, 1992

33. J.F. Archard, Contact and Rubbing of Flat Surface, J. Appl. Phys., 1953, 24(8), p 981-988

34. X.S. Wan, S.S. Zhao, Y. Yang, J. Gong, and C. Sun, Effects of Nitrogen Pressure and Pulse Bias Voltage on the Properties of Cr-N Coatings Deposited by Arc Ion Plating, Surf. Coat. Technol., 2010, 204, p 1800 1810

35. M. Chen, D. Wu, W. Chen, and S. Zhang, Structural Optimisation and Electrochemical Behaviour of AlCrN Coatings, Thin Solid Films, 2016, 612, p 400-406

36. I.W. Park, D.S. Kang, J.J. Moore, S.C. Kwon, J.J. Rha, and K.H. Kim, Microstructures, Mechanical Properties, and Tribological Behaviors of Cr-Al-N, Cr-Si-N, and Cr-Al-Si-N Coatings by a Hybrid Coating System, Surf. Coat. Technol., 2007, 201, p 5223-5227

37. U. Helmersson, M. Lattemann, J. Bohlmark, A.P. Ehiasarian, and J.T. Gudmundsson, Review: Ionized Physical Vapor Deposition (IPVD): A Review of Technology and Applications, Thin Solid Films, 2006, 513, p $1-24$
38. B. Warcholinski, A. Gilewicz, J. Ratajski, Z. Kuklinski, and J. Rochowicz, An Analysis of Macroparticle-Related Defects in the $\mathrm{CrCN}$ and CrN Coatings in Dependence on the Substrate Bias Voltage, Vacuum, 2012, 86, p 1235-1239

39. S. Creasey, D.B. Lewis, I.J. Smith, and W.D. Munz, SEM Image Analysis of Droplet Formation During Metal Ion Etching by a Steered Arc Discharge, Surf. Coat. Technol., 1997, 97, p 163-175

40. W.D. Munz, I.J. Smith, D.B. Lewis, and S. Creasey, Droplet Formation on Steel Substrates During Cathodic Steered Arc Metal Ion Etching, Vacuum, 1997, 48, p 473-481

41. C. Rebholz, H. Ziegele, A. Leyland, and A. Matthews, Structure, Mechanical and Tribological Properties of Nitrogen-Containing Chromium Coatings Prepared by Reactive Magnetron Sputtering, Surf. Coat. Technol., 1999, 115, p 222-229

42. M. Hirai, Y. Ueno, T. Suzuki, W. Jiang, C. Grigoriu, and K. Yatsui, Characteristics of (Cr1-x, Alx)N Films Prepared by Pulsed Laser Deposition, Jpn. J. Appl. Phys., 2001, 40, p 1056-1060

43. T. Li, M. Li, and Y. Zhou, Phase Segregation and Its Effect on the Adhesion of Cr-Al-N Coatings on K38G Alloy Prepared by Magnetron Sputtering Method, Surf. Coat. Technol., 2007, 201, p 7692-7698

44. J. Takadoum and H. Houmid Bennani, Influence of Substrate Roughness and Coating Thickness on Adhesion, Friction and Wear of TiN Films, Surf. Coat. Technol., 1997, 96, p 272-282

45. K. Valleti, C. Rejin, and S.V. Joshi, Factors Influencing Properties of CrN Thin Films Grown by Cylindrical Cathodic Arc Physical Vapor Deposition on HSS Substrates, Mater. Sci. Eng. A, 2012, 543, p 155-161

46. F. Cai, S. Zhang, J. Li, Z. Chen, M. Li, and L. Wang, Effect of Nitrogen Partial Pressure on Al-Ti-N Films Deposited by Arc Ion Plating, Appl. Surf. Sci., 2011, 258, p 1819-1825

47. A.Y. Adesina, Z.M. Gasem, and F.A. Al-Badour, Characterization and Evaluation of AlCrN Coated FSW Tool: A Preliminary Study, $J$. Manuf. Process., 2017, 25, p 432-442

48. O. Lupicka and B. Warcholinski, The Adhesion of $\mathrm{CrN}$ Thin Films Deposited on Modified 42CrMo4 Steel, Adv. Mater. Sci. Eng., 2017, h ttps://doi.org/10.1155/2017/4064208

49. J.L. Mo and M.H. Zhu, Tribological Oxidation Behaviour of PVD Hard Coatings, Tribol. Int., 2009, 42, p 1758-1764

50. J.L. Lin, W.D. Sproul, and J.J. Moore, Tribological Behavior of Thick CrN Coatings Deposited by Modulated Pulsed Power Magnetron Sputtering, Surf. Coat. Technol., 2012, 206, p 2474-2483

51. V. Moraes, H. Riedl, R. Rachbauer, S. Kolozsvari, M. Ikeda, L. Prochaska, S. Paschen, and P.H. Mayrhofer, Thermal Conductivity and Mechanical Properties of AlN-Based Thin Films, J. Appl. Phys., 2013, 119, p 225304

52. A.M. Hofmeister, Thermal Diffusivity and Thermal Conductivity of Single-Crystal $\mathrm{MgO}$ and $\mathrm{Al}_{2} \mathrm{O}_{3}$ and Related Compounds as a Function of Temperature, Phys. Chem. Miner., 2014, 41, p 361-371

53. A. Liu, J. Deng, H. Cui, Y. Chen, and J. Zhao, Friction and Wear Properties of TiN, TiAlN, AlTiN and CrAlN PVD Nitride Coatings, Int. J. Refract. Met. Hard Mater, 2012, 31, p 82-88

54. J. Lin, B. Mishra, J.J. Moore, W.D. Sproul, and J.A. Rees, Effects of the Substrate to Chamber Wall Distance on the Structure and Properties of CrAlN Films Deposited by Pulsed-Closed Field Unbalanced Magnetron Sputtering (P-CFUBMS), Surf. Coat. Technol., 2007, 201, p 6960-6969

55. Y.Y. Chang, S.Y. Weng, C.H. Chen, and F.X. Fu, High Temperature Oxidation and Cutting Performance of AlCrN, TiVN and Multilayered AlCrN/TiVN Hard Coatings, Surf. Coat. Technol., 2017, 332, p 494 503

56. B. Warcholinski and A. Gilewicz, The Properties of Multilayer CrCN/ CrN Coatings Dependent on Their Architecture, Plasma Process. Polym., 2011, 8, p 333-339

57. M. Haršáni, N. Ghafoor, K. Calamba, P. Zacková, M. Sahul, T. Vopát, L. Satrapinskyy, M. Čaplovičová, and L'. Čaplovič, Adhesive-Deformation Relationships and Mechanical Properties of nc-AlCrN/a-SiN ${ }_{x}$ Hard Coatings Deposited at Different Bias Voltages, Thin Solid Films, 2018, 650, p 11-19

Publisher's Note Springer Nature remains neutral with regard to jurisdictional claims in published maps and institutional affiliations. 